\title{
Study on food consumption pattern and blood profile of urban women
}

\author{
A.M. B hoyar and Rohini Devi
}

\begin{abstract}
Women is the center figure for the health and welfare of the family. In the present study a total of 180 urban women were selected by stratified random technique, equal distribution existed between working and non - working groups. A survey was carried out to evaluate the socio - economic status of the selected women. The diet survey by the recall method food intakes pattern revealed that they consumed less amount of foods than the balanced diet except for fats and oils, fats and oils consumption ranged 43.00 to 61.66 $\mathrm{g}$. The nutrient intake registered deficit in the consumption of energy, protein and iron ranging 1432 to 1802 (Kcal); 37.66 to 45.66 (g); 14.53 to $16.33(\mathrm{mg})$, respectively whereas fat, calcium, phosphorus and vitamin $\mathrm{C}$ were recorded more than the recommended dietary allowances. Significant difference noted only for energy. Blood profiles showed range of PCV 39.13 to 44.6 per cent, Hb 8.50 to $9.00 \mathrm{~g}, \mathrm{RBC} 4.50$ to $4.70 \mathrm{~m} / \mathrm{mm}^{3}$, MCV 84.9 to $111.31 \mathrm{fl}, \mathrm{MCH} 18.43$ to $19.42 \mathrm{pg}$ and $\mathrm{MCHC} 20.62$ to 23.21 showing the prevalence of anaemia among them.
\end{abstract}

Key Words : Anthropometry, Nutritional status, Working and nonworking women

How to cite this article : Bhoyar, A.M. and Devi, Rohini (2014). Study on food consumption pattern and blood profile of urban women. Food Sci. Res. J., 5(2): 161-164. 